\title{
ARTÍCULOS
}

\section{DOS PODERES ENFRENTADOS EN LA NUEVA ESPAÑA: IGLESIA VS. MONARQUÍA DURANTE EL VIRREINATO DEL MARQUÉS DE VILLAMANRIQUE $(1585-1590)^{1}$.}

\author{
María Vicens Hualde \\ Universitad Autónoma de Madrid \\ mvicensh@gmail.com
}

Resumen: La concreción de la autoridad otorgada a la Corona española mediante el Patronato Real colisionó a menudo con la idea que las autoridades eclesiásticas tenían de su autonomía respecto al poder político. Este artículo analiza la importancia que tuvo este problema con un virrey que intentó reforzar la autoridad y prerrogativas reales que representaba y los enfrentamientos que se produjeron con las autoridades eclesiásticas que influyeron, en último término, en la caída del virrey y en la dureza de la sentencia que le fue impuesta.

Palabras clave: Iglesia, Virreinato, Nueva España, Marqués de Villamanrique, Patronato Regio, Arzobispo Moya de Contreras, siglo XVI.

Tittle: TWO POWERS FACED IN NEW SPAIN: CHURCH VS. MONARCHY DURING THE VICEROYALTY OF THE MARQUIS OF VILLAMANRIQUE (1585-1590).

Abstract: The authority granted to the Spanish crown through the Royal Patronage conflicted with the idea of the ecclesiastical authority having its own autonomy from the political power. This article analyzes the importance of this problem with a viceroy who attempted to strengthen the royal authority and prerogatives that he represented. The struggles with the ecclesiastic authority ultimately influenced in the fall of the viceroy and the hard sentence that he received.

Keywords: Church, Viceroyalty, New Spain, Marquis of Villamanrique, Royal Patronage, Archbishop Moya de Contreras, $16^{\text {th }}$ century.

\section{Introducción}

Es bien conocida la interrelación Iglesia-monarquía en toda la estructura de gobierno hispánica en América. Ya desde los primeros tiempos del descubrimiento se puso de manifiesto el empeño de los Reyes Católicos por justificar

\footnotetext{
${ }^{1}$ Este artículo es parte de mi tesis doctoral, sobre el I marqués de Villamanrique, virrey de la Nueva España, recientemente presentada en la UAM.
}

Recibido: 31-08-2019

Aceptado: 09-09-2019

Cómo citar este artículo: VICENS HUALDE, María. Dos poderes enfrentados en la Nueva España: Iglesia vs. Monarquía durante el Virreinato del Marqués de Villamanrique (1585-1590). Naveg@mérica. Revista electrónica editada por la Asociación Española de Americanistas [en línea]. 2020, n. 24. Disponible en: <http://revistas.um.es/navegamericas. [Consulta: Fecha de consulta]. ISSN 1989-211X. 
teológicamente la conquista de las Indias, como medio para propagar en ellas la fe católica. Y así, apenas Colón regresó de su primer viaje dando a la Corte noticias de las nuevas tierras y de sus habitantes paganos, los monarcas le ordenaron procurase que los indios "sean bien informados de las cosas de nuestra santa fe"2.

Utilizando con éxito su diplomacia ante la Santa Sede, los monarcas consiguieron del Papa (a la sazón el setabense Alejandro VI) el reconocimiento y la confirmación, por parte de la Iglesia, de esta misión para la Corona de Castilla, mediante las bulas Inter caetera, Eximiae devotionis, Piis fidelium y Dudum siquidem que, a grandes rasgos, legitimaban el dominio de las tierras a cambio de asumir su evangelización. En bulas posteriores ${ }^{3}$, se fue determinando definitivamente lo que constituiría el Regio Patronato, en virtud del cual los reyes de Castilla recibieron la representación papal con el poder de enviar misioneros, sustentar al clero, erigir iglesias, administrar los diezmos secularizados, presentar personas para los beneficios eclesiásticos y facultad para poner límites a las diócesis ${ }^{4}$. En 1539 Carlos $\checkmark$ imponía el regium exequatur o pase regio, para que pasaran por sus manos las peticiones de los prelados a la Santa Sede y los documentos pontificios para ser ejecutados.

De esta manera quedaba en poder de la Corona la organización de la Iglesia en Indias, la creación y administración de las diócesis y el nombramiento de sus ministros. Como puede comprenderse, en el ejercicio de tan amplias facultades se registraron numerosos conflictos de competencias. La cada vez más elástica interpretación del Regio Patronato llevó a la teoría del Regio Vicariato que convertía al soberano en un vicario espiritual del Papa para todos los asuntos religiosos. Así escribía el obispo de Cuzco, Sebastián de Lartaún al rey en 1583: "en las Indias casi no hay Iglesia, porque Vuestra Magestad se lo es todo"5.

Para comprender las relaciones entre virreyes y obispos es interesante examinar cómo eran consideradas ambas figuras por sus contemporáneos. Siguiendo la idea de que el rey recibía su poder y autoridad directamente de Dios, siendo el virrey el vicario real también lo sería de esa delegación divina. Francisco Suárez reconocía

\footnotetext{
${ }^{2}$ Archivo General de Indias (en adelante AGI), Indiferente general, 418, lib. 1, f. 192v. Instrucciones del rey y la reina a don Cristóbal Colón.

${ }^{3}$ Ullius fulcite praesidio (1504), Universalis ecclesiae (1508), y sobre todo la bula Exponis nobis nuper fecistis, conocida como Omnimoda de Adriano VI (1522); TORRES, Pedro. La bula omnímoda de Adriano VI. Madrid: Instituto Santo Toribio de Mogrovejo; Consejo Superior de Investigaciones Científicas, 1948.

${ }^{4}$ Para los conceptos de Regio Patronato y Regio Vicariato, vid. HERA PÉREZ CUESTA, Alberto de la. El patronato y el vicariato regio en Indias. En: BORGES, Pedro (dir.). Historia de la Iglesia en Hispanoamérica y Filipinas. Vol 1. Madrid: Biblioteca de Autores Cristianos, 1992; HERA PÉREZ CUESTA, Alberto de la. El regio vicariato de Indias en las bulas de 1493. Anuario de Historia del Derecho Español. 1959, n. 29, pp. 317-350. Anterior en el tiempo, pero muy relevante como referencia, LETURIA, Pedro. El Regio Vicariato de Indias y los comienzos de la congregación de Propaganda Fide. Spanische Forschungen Der Görresgesellschaft. Vol. I. 1929, pp. 133-177.

${ }^{5}$ En el mismo sentido se recoge una frase de Santo Toribio de Mogrovejo, el 23 de abril de 1584, al rey: "Si para reformar nuestros clérigos, donde tanta necesidad hay, no tenemos mano los prelados, de balde nos juntamos los prelados, y aun de balde somos obispos"; LUQUE ALCAIDE, Elisa. La Iglesia, semilla de solidaridad universal en la familia humana. En: PELLITERO IGLESIAS: Ramiro (dir.). La Iglesia como familia de Dios. Madrid: Rialp, 2010, p. 234.
} 
que los reyes eran vicarios de Dios, pero solo en lo referente a asuntos temporales, mientras que en los espirituales esta condición era exclusiva de los obispos y el Papa $^{6}$. A mediados del XVII Gaspar de Villarroel, primer obispo de Santiago de Chile y más tarde de Arequipa, escribía sobre la cuestión de la fidelidad de los obispos afirmando que "cuando van vestidos de obispos quedan despojados de su vasallaje", señal de que aún los monarcas no podían dar por garantizada su autoridad sobre el clero ${ }^{7}$.

¿En qué posición quedaba el virrey ante esta situación? Como alter ego del monarca era un vicepatrono y tenía, al menos en teoría, el poder de ejercer su autoridad en todos los aspectos anteriormente señalados. En el caso del marqués de Villamanrique las circunstancias concretas de la Iglesia y el virreinato en el momento de su llegada hicieron que fuera especialmente difícil hacer valer esa autoridad y marcaron su gobierno hasta el final del mismo. Un año después de su llegada a Nueva España, escribió a Felipe II sus impresiones sobre la disposición de los prelados, resaltando que la distancia de la figura real dificultaba su capacidad de actuación, así como su propósito de solventar la situación:

"Todas las personas eclesiásticas de este reyno por lo general an menester que entiendan el rrespecto que an de tener a V. Magd. y a sus reales ministros, porque tienen muy poco y es de muy gran ynconviniente estando V. Magd. tan lejos. Mas mientras yo viniere en este reyno, toda la gente del a de tener muy cerca el nombre de V.Magd de qualquier estado que sean"8.

\section{2. Álvaro Manrique de Zúñiga, marqués de Villamanrique}

Álvaro Manrique de Zúñiga, I marqués de Villamanrique, fue nombrado virrey de Nueva España en 1585. A pesar de pertenecer a una de las familias más relevantes de la nobleza, la de los duques de Béjar, el hecho de ser el quinto hijo mermaba sus posibilidades de acceder a altos cargos. Una decidida estrategia de su madre, mediante la negociación de alianzas matrimoniales y creación de mayorazgos, le proporcionó los medios para ascender en la jerarquía social. Tras conseguir, por donación materna, la titularidad de su propio mayorazgo, don Álvaro solicitó la concesión del hábito de la Orden de Santiago, el cual le fue otorgado en 1564. El siguiente paso fue concertar un ventajoso matrimonio con Blanca Enríquez de Velasco, hija del conde de Nieva, virrey del Perú y sobrina del virrey de Nueva España Martín Enríquez, enlace que le aportó una nada despreciable dote. Don Álvaro prestó sus servicios al rey en la ciudad de Sevilla como alcalde mayor y, en 1575, Felipe II le concedió el esperado título nobiliario, marqués de Villamanrique. Durante la campaña de Portugal tomó parte en la defensa de la frontera del sur, en el ejército que comandó su sobrino, el duque de Medina Sidonia. Finalmente, vio recompensados sus servicios cuando el monarca le nombró virrey de la Nueva España.

\footnotetext{
${ }^{6}$ Sobre el desarrollo de dicho discurso, vid. el capítulo "In the service of two majesties", en CAÑEQUE, Alejandro. The King's Living Image: The Culture and Politics of Viceregal Power in Colonial Mexico. Nueva York: Routledge, 2004, pp. 79 y ss.

${ }^{7}$ Ibídem, p. 90.

${ }^{8}$ AGI, México, 20, 119, f. 20. Carta del marqués de Villamanrique a Felipe II. México, 17 de diciembre de 1585.
} 


\section{La Iglesia en Nueva España a la llegada del virrey Villamanrique}

El primer obispado en tierra firme se había fundado en 1513, Santa María de la Antigua del Darién, trasladada a Panamá en 1524. En Nueva España se fundó el de Tlaxcala en 1519 y ya en 1530 el de México, todos ellos como diócesis dependientes de Sevilla. Al tener que plantear todos los problemas y consultas a la consideración del arzobispo en España, los asuntos se demoraban considerablemente, por lo que se proyectó crear una archidiócesis en América. En 1544 el Consejo de Indias propone Santo Domingo, México y Lima como arzobispados, lo cual fue aceptado y quedaron así erigidas las tres grandes archidiócesis en Indias.

Al arzobispado de México pertenecían las diócesis de Tlaxcala (Puebla de los Ángeles), Antequera de Oaxaca, Michoacán, Guatemala, Chiapas y Nueva Galicia.

En la ciudad de México había cuatro distritos parroquiales, además de las iglesias dependientes de conventos y fundaciones de las órdenes regulares, ermitas y capellanías. Asimismo, dependían de la Iglesia las principales instituciones educativas, como la Real y Pontificia Universidad o los colegios de Santa Cruz de Tlatelolco, fundado por los franciscanos, y el de San Pablo en la parroquia de la Vera Cruz, por los agustinos. La segunda diócesis en importancia, aunque mayor que la de México en cuanto a extensión y población, era la de Puebla-Tlaxcala, con cuatro parroquias en Puebla de los Ángeles, tres conventos de religiosos y 121 pueblos de indios. La de Nueva Galicia, o Jalisco, contaba con once beneficios de clérigos en pueblos de indios, 33 en pueblos de españoles y dos colegios a cargo de la Compañía de Jesús (en Guadalajara y Zacatecas).

En este momento en particular, a finales del siglo XVI, lo que añadió tensión a la relación con el virrey fue la especial circunstancia del arzobispo de México, Pedro Moya de Contreras. Doctorado en Derecho civil y canónico en Salamanca, había sido nombrado inquisidor en España. El 25 de enero de 1569 Felipe II emitió una real cédula por la que establecía el tribunal de la Inquisición en Nueva España, y Moya de Contreras fue nombrado primer inquisidor del mismo. El Tribunal del Santo Oficio se fundó en México el 4 de noviembre de 1570. Poco después, tras el fallecimiento del arzobispo Montúfar, fue nombrado arzobispo el 15 de septiembre de 1582, ocupando la sede episcopal en la catedral de México el 8 de diciembre. Su fulgurante carrera apenas había comenzado.

Durante el mandato de Lorenzo Suárez de Mendoza, conde de La Coruña, los problemas del virrey con los oidores de México provocaron que Felipe II nombrase en 1583 visitador general, con amplios poderes, a Moya de Contreras, pues "era

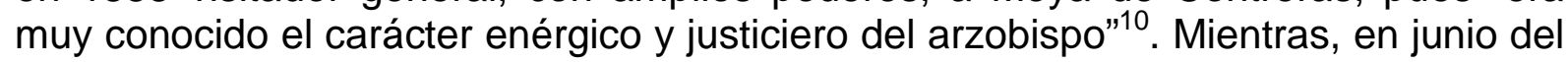
mismo año, fallecía súbitamente el virrey y la audiencia de México tomó las riendas del gobierno de forma provisional. Llegada a España la noticia, el rey decidió nombrar virrey interino al arzobispo hasta que se decidiera el nombramiento de la

\footnotetext{
${ }^{9} \mathrm{Si}$ se citan específicamente estas diócesis es por ser los tres focos principales de conflicto con la autoridad virreinal.

${ }_{10}$ RIVA PALACIO, Vicente. México a través de los siglos: el virreinato; historia de la dominación española en México desde 1521 á 1808. Ciudad de México: Cumbre, 1977, p. 437.
} 
persona idónea para el cargo, del que tomó posesión el 25 de septiembre de $1584^{11}$.

Por tanto, a la llegada de Villamanrique, Moya ostentaba todos los cargos de mayor poder en Nueva España, pues era también presidente del tribunal de la Inquisición, visitador general y virrey interino, lo que suponía ser además gobernador, capitán general y presidente de la audiencia ${ }^{12}$. Así, la llegada del nuevo virrey, con la consiguiente cesión de autoridad por parte del arzobispo, no iba a resultar fácil para ninguno de los dos.

\section{Publicación de las actas del Concilio}

El III Concilio Provincial Mexicano fue el más importante de los celebrados durante el siglo XVI, tanto por la cantidad y calidad de sus asistentes, como por sus contenidos. En él se sentaron las bases de la doctrina, catequesis y administración de sacramentos a la población indígena ${ }^{13}$. Es de resaltar el hecho de que el siguiente concilio no se celebró hasta 1771. Por tanto, las conclusiones que se implantaron en 1585 se mantuvieron vigentes a lo largo de casi dos siglos ${ }^{14}$. Su celebración se debió a la iniciativa del arzobispo de México, quien veía la necesidad de reformar algunos aspectos de la disciplina eclesiástica, mejorar la situación de los indios y poner en práctica los acuerdos tomados en el Concilio de Trento. El proyecto consiguió el beneplácito del rey, quien escribió a los prelados a fin de expresar sus deseos a la congregación ${ }^{15}$. En el mensaje les conminaba a atender las instrucciones que llevaba el marqués de Villamanrique como su representante, pues la asistencia del virrey fue una exigencia expresada reiteradamente por el

\footnotetext{
${ }^{11}$ Aunque la implicación del arzobispo en asuntos civiles empezó mucho antes de su nombramiento como virrey interino. Desde el momento de su llegada escribió periódicamente a Juan de Ovando, relatando sus impresiones y opiniones, no solo sobre asuntos eclesiásticos, sino sobre cuestiones ajenas a su cargo. POOLE, Stafford. Pedro Moya de Contreras: Catholic Reform and Royal Power in New Spain, 1571-1591. Berkeley; Los Angeles; Londres: University of California Press, 1987, p. 118.

${ }^{12}$ Las difíciles relaciones con el arzobispo se han tratado en VICENS HUALDE, María. Guerra de cortesías: el ceremonial como arma en el conflicto entre el virrey marqués de Villamanrique y el arzobispo Moya de Contreras. Temas Americanistas. 2018, n. 40, pp. 119-139.

13 "El III Mexicano, a pesar de sus sombras, representó la coronación de la evangelización en México, iniciada ya en la misma conquista y de forma sistemática en 1524, con la llegada de los Doce Apóstoles franciscanos"; MARTÍNEZ FERRER. Luis. Fuentes e historiografía del III concilio provincial mexicano (1585). En: SARANYANA, Josep Ignasi; LAMA, Enrique de la y LLUCH-BAIXAULI, Miguel (eds.). Qué es la historia de la Iglesia: XVI Simposio Internacional de Teología de la Universidad de Navarra. Pamplona: Servicio de Publicaciones de la Universidad de Navarra, 1996, p. 366. Sin embargo, su acogida en Nueva España estuvo rodeada de quejas en varios ámbitos: órdenes mendicantes, clero secular y diferentes instituciones mostraron su disconformidad con las medidas acordadas por diversas razones. Aunque escapa al tema central de este artículo, es interesante ver al respecto, RAMÍREZ MENÉNDEZ, Jessica. Fundar para debilitar. El obispo de Puebla y las órdenes regulares (1586-1600). Estudios de historia novohispana. 2013, n. 49, pp. 39-82.

${ }^{14}$ Por otra parte, en la Nueva España fue el único que recibió aprobación real y pontificia, "por lo que se trató de la única normativa de la provincia eclesiástica mexicana hasta 1896, cuando se celebró el V Concilio"; PÉREZ PUENTE, Leticia. Dos proyectos postergados. El Tercer Concilio Provincial Mexicano y la secularización parroquial. Estudios de Historia Novohispana. 2006, n. 35, pp. 17-45.

15 Por una cuestión logística se retrasó el envío del mensaje, "mandé escribir las cartas que me pedisteis para los prelados diocesanos y, por no haber habido ocasión, no se os han enviado; y porque conforme al tiempo que los señalasteis en vuestras convocatorias estarán ya juntos, y así no será menester escribirles en particular, escribo en general a toda la congregación"; AGI, México, 1064, f. 152v. Cédula de Felipe II al arzobispo de México. Barcelona, 13 de mayo de 1585.
} 
monarca ${ }^{16}$. En la cédula dirigida al arzobispo el rey hacía especial énfasis en dos cuestiones, como fueron el condicionante de la licencia real para la aplicación de las conclusiones del concilio y la consideración del Patronato Real ${ }^{17}$.

\begin{abstract}
"Me parescio muy bien y [...] escrivo en general a toda la congregación, lo que vereys por la carta que os dara el marques de Villamanrique, a quien he proveydo por mi virrey de esas provincias, el qual ha de asistir, en mi nombre, en el Concilio, como se lo escrivo y el os dira" [...] "y pues dezis que no se executara ninguna cossa hasta que yo lo vea y de licencia para ello, no habrá mas que advertiros de que mireys mucho por lo que toca a la conservación de mi patronazgo"18.
\end{abstract}

Las sesiones se fueron desarrollando normalmente a lo largo de siete meses durante los cuales se trataron temas de relevancia, desde los sacramentos, la reforma del clero y la uniformidad de la doctrina, con especial incidencia en la defensa de los indios. Los trabajos terminaron a mediados de septiembre de 1585, poco después de la llegada de Villamanrique a Nueva España.

Los problemas comenzaron al exigir los prelados la inmediata publicación y ejecución de los decretos conciliares, a pesar de las advertencias que habían recibido, por parte de un secretario de la audiencia, de que no tenían la aprobación real para hacerlo. El virrey traía instrucciones específicas del soberano de que "nada se execute hasta que yo lo vea y de licencia para ello"19, por lo que requirió a los padres conciliares que entregaran el original de las actas, a fin de enviarlo a España para ser sometido al escrutinio real. Los prelados cedieron el documento, no sin antes sacar un traslado, por orden del arzobispo, copia que utilizaron para efectuar una lectura pública en la catedral de México. De esta manera los prelados eludieron de facto las órdenes reales, aunque evitando un enfrentamiento directo, como habría ocurrido de haber esperado apenas unos días más, cuando se produjera la entrada del virrey en la Ciudad de México.

\footnotetext{
${ }^{16}$ AGI, México, 1064, f. 156r. Cédula de Felipe II al marqués de Villamanrique. Barcelona, 13 de mayo de 1585. Este último punto resultaba de la mayor importancia para el monarca, a juzgar por su insistencia, ya que en varias ocasiones reiteró la orden de que el virrey asistiera al concilio en su representación para velar por sus intereses. En otras dos cédulas de 13 de mayo, así como en otra de Monzón, 14 de julio del mismo año, requiere al virrey que procure el buen funcionamiento del concilio y defienda los intereses de la corona como si fuera el mismo rey, al tiempo que ordena a los prelados que tengan en cuenta todo lo que diga el virrey en sus intervenciones; AGI, México, 1064, f. $155 r$ a $156 r$; f. 156r y v; , f. 157r y ff. 166v-168r. Cédulas al virrey Villamanrique, al inquisidor Bonilla, y a los prelados del concilio, respectivamente. Por otra parte, se recoge en la Recopilación, Libro I, Título VIII, Ley II, "Que los virreyes, presidentes o gobernadores asistan en los concilios provinciales en nombre del rey"; Recopilación de Leyes de los Reynos de las Indias. Por lulián Paredes. En Madrid. Año de 1681, p. 42.

${ }^{17}$ AGI, México, 1064, f. 152v. Real cédula de Felipe II al arzobispo de México. Barcelona, 13 de mayo de 1585.

${ }^{18}$ La asistencia del virrey fue una exigencia expresada reiteradamente por el rey: "os encargo y mando assistays personalmente y por mi y en mi nombre [...] en el qual haveys de tener el lugar que se acostumbra a dar a los que representando mi real persona an assistido en semejantes concillios"; AGI, México, 1064, ff. 152v.-155r. Real cédula de Felipe II al arzobispo de México. Barcelona, 13 de mayo de 1585.

${ }^{19}$ AGI, México, 1064, f. 156. Real cédula al marqués de Villamanrique. Barcelona, 13 de mayo de 1585.
} 
El arzobispo justificó su conducta declarando que los acontecimientos se habían precipitado por la necesidad de los obispos de regresar a sus diócesis, así como por la tardanza del virrey, quien, debido a la enfermedad que le aquejó durante su travesía, se había visto obligado a hacer varios altos en el camino y por "no haber avisado de la orden que traía de Vuestra Majestad"20. Este último argumento era fácilmente rebatible, pues el secretario de la audiencia, que había recibido el virrey en Perote, había llevado las órdenes expresas de este hasta México, invocando la mencionada cédula real ${ }^{21}$. Además, en la misma fecha el marqués había remitido una carta al arzobispo felicitándose por la finalización de los trabajos del concilio y advirtiéndole que se abstuviese de su publicación ${ }^{22}$. También alegaba que se habían producido amenazas de los obispos de no firmar las actas del concilio, y que la copia la hizo para enviarla al rey, "y considerando el escándalo que resultaría si con precisión se les prohibiera la publicación, se tuvo por mas conveniente disimular que impedirla"23. Esta iniciativa que, en el fondo, no dejaba de ser un ardid para soslayar la autorización real, se presentó como solución de compromiso en la polémica con los obispos ${ }^{24}$.

\section{Enfrentamientos por el Regio Patronato}

Como se ha dicho anteriormente, los privilegios concedidos por la Iglesia a la Corona se concretaron en el Regio Patronato y, a través de la delegación de estas facultades, la organización de la Iglesia en los nuevos territorios quedó, prácticamente, en manos de la Corona. Las relaciones de Villamanrique con el episcopado fueron tensas en la mayoría de los casos, debido a las competencias que se arrogaban sin tener en cuenta el Patronato Real, cuya representación ostentaba el virrey y, en el caso de Villamanrique, un virrey regalista ${ }^{25}$. Así, poco después de llegar a México, el virrey escribía al monarca sus impresiones sobre la disposición de los obispos en este tema:

\footnotetext{
${ }^{20}$ AGI, México, 336-B, f. 184. Carta de Pedro Moya de Contreras al rey. México, 1 de diciembre de 1585.

${ }^{21}$ El secretario Diego Gentil se entrevistó con Villamanrique en el pueblo de Perote, donde recibió las instrucciones del nuevo virrey en el sentido de que "si el concilio se hubiese publicado, lo que yo no puedo creer", no se ejecutase ningún decreto "hasta que su majestad lo vea y de licencia para ello", aunque su respuesta no llegó a tiempo; AGI, México, 1254, f. 32. Carta del marqués de Villamanrique a la audiencia de México, Perote, 22 de octubre de 1585.

22 "[...] me dijeron también que V S le había mandado publicar luego, y aunque yo no lo doy crédito a esto postrero, por ser una cosa tan contra el servicio de su majestad y de sus reales mandamientos, me ha parecido advertir a $V S^{\underline{a}}$ que no se haga, porque yo traigo orden se su majestad de lo que en esto se ha de hacer". Ibídem, f. 34; Carta del marqués de Villamanrique a Pedro Moya de Contreras, Perote, 22 de octubre de 1585.

${ }^{23}$ AGI, México, 336-B, 184. Carta de Pedro Moya de Contreras al rey. México, 1 de diciembre de 1585.

${ }^{24}$ Vid. ORTIZ TREVIÑO, Rigoberto Gerardo. El Tercer Concilio Provincial Mexicano o como los obispos evadieron el Real patronato indiano. En Anuario Mexicano de Historia del Derecho. 2003, n. 15, pp. 77-94.

25 "La infame residencia de Villamanrique [...] representará un ejemplo muy notable de la venganza de los eclesiásticos contra un virrey regalista”; así lo define POOLE, Stafford. La visita de Moya de Contreras. En: Memoria del Segundo Congreso Venezolano de Historia. Vol. 2. Caracas: 1975, p. 423.
} 
"Todavía ay muchas cosas que poner en orden con los prelados para que acaben de entender que el derecho del patronazgo en todas las Indias pertenece a V. Mgd., y asi voy componiendo esto poco a poco de la manera que me parece que conviene al servi(cio) de V.Mgd"26.

La distancia de la metrópoli y la dispersión geográfica en un inmenso territorio favorecían la falta de control y los obispos ejercían su autoridad con una autonomía que no estaban dispuestos a ceder. De todo ello advirtió el marqués a su sucesor, Luis de Velasco, al final de su mandato, afirmando que:

"[...] una de las cosas que hallé perdidas y relajadas cuando llegué a esa tierra fue el patronazgo de S.M, porque se lo tenían usurpado los prelados. Y así no pedían presentación para los más de los oficios y dejaban de guardar la forma del patronazgo"27.

Como se desprende de la lectura de los documentos, estas tensiones con el episcopado se centraron sobre todo en Moya de Contreras y Diego Romano, titulares de las diócesis de México y Puebla, respectivamente ${ }^{28}$. De modo muy diferente se refería el virrey a otros obispos, como los de Oaxaca y Michoacán, con los mantuvo una relación más fluida, circunstancia que el marqués achacaba a la humildad que les confería su condición de frailes y su lealtad al monarca:

"[...] porque los obispos de Mechoacan y Guaxaca como son frailes y de buena vida y exemplo están mas humildes y subjetos a los mandamentos y ordenes de V. Magd y ay tan pocas pesadumbres con ellos quanto muchas con los demás [...] aunque con los de Guaxaca, que es don fray B(artolo)mé de Ledesma, y el de Mechoacán, don fray Ju(an) de Medina Rincón ay bien poco que hazer, porque son muy vasallos de V.Mgd. y aficionadissimos a su Real servicio. Y así cumplen bien lo que en nombre de V.Mgd. se les ordena en cuanto a esto, en especial don Fray B(artolo)mé de Ledesma, que es la persona que en todas estas yndias de los eclesiásticos con más respecto ama el servicio de V.Mgd. y con cuanto del se le ordena" ${ }^{\prime 2}$.

En este último párrafo, la frase "como son frailes y de buena vida", puede resultar una de las claves que aclaran las decisiones del virrey, pues resalta las diferencias de los regulares con los obispos pertenecientes al clero secular, como eran Moya de Contreras y Diego Romano. Las diferencias entre ambas ramas provocaron, a lo largo de su mandato, no pocas situaciones de conflicto. En cualquier caso, cabe señalar la circunstancia de que los obispos no formaban un

${ }^{26}$ AGI, México, 20, 119, f. 30. Carta del marqués de Villamanrique a Felipe II. México, 17 de diciembre de 1585 .

${ }_{27}$ Advertimientos generales que el Marqués de Villamanrique dio a Luis de Velasco. 14 de febrero de 1590, en HANKE, Lewis. Los virreyes españoles en América durante el gobierno de la Casa de Austria. Madrid: Atlas, 1977, p. 282.

28 "En algunas cartas tengo scripto a V. Md. Lo mucho que sienten los prelados desta tierra q(ue) se guarde y observe a V. Md su Real Patronazgo y que en todo quanto pueden adquirillo para si lo hacen y particularmente el arçobispo y su governador y el ob(is)po de la puebla [...] oponiendosse a qualquiera cossa que ssea tocante al patronazgo de V.Md, y en qualquiera casso y acresçimiento, y de aquí nascen otras muchas ocasiones de poco respeto, que como no aviendole, no se puede gobernar"; AGI, México, 21, 37. Carta de Villamanrique al rey. México, 30 de junio de 1588.

${ }_{29} \mathrm{AGI}$, México, 21, 3. Carta del marqués de Villamanrique al rey. México, 4 de febrero de 1587. 
cuerpo unitario, sino que entre ellos existían diferencias y se creaban distintas redes de apoyo en el seno de la comunidad episcopal.

\title{
6. Provisión de cargos y beneficios
}

La provisión de cargos eclesiásticos era uno de los temas de mayor fricción entre ambas autoridades. Las diferencias de parecer, en cuanto a las competencias derivadas de este privilegio del patronato, no eran nuevas. Tiempo atrás, bajo el mandato del virrey Martín Enríquez, Moya había escrito al soberano sobre este particular, diciendo que en virtud de la autoridad y "humos" (sic) que les daba el patronazgo, algunos usurpaban la autoridad y privilegios de la Iglesia.

"El virrey da licencia a los frailes para que funden monasterios. Envió nombramiento que hizo el Sr. Juan Chávez, de Cura y Capellán del puerto de San Juan de Ulúa, para baptizar, confesar y hacer todo lo demás del oficio de cura. Alcanzan hasta los muy idiotas ser esto ajeno a la jurisdiçion del virrey. Estan muchos escandaliçados de ver esta novedad, de donde nace que algunos entienden que todo lo puede el virrey en lo eclesiástico y seglar"30.

El Regio Patronato establecía que la presentación de los cargos era prerrogativa real; en el caso de Nueva España, dependían del virrey, su presentación y confirmación. El nombramiento, por tanto, correspondía al virrey, pero las atribuciones espirituales eran incumbencia de la Iglesia. Una vez más, los límites de las competencias provocaban fricciones frecuentes entre ambas autoridades. Pero, como explicaba Villamanrique, los obispos habían encontrado una fórmula para eludir el control real, nombrando vicarios interinos para cambiarlos cuando les convenía, alegando que no eran designaciones definitivas. Con esta fórmula el virrey quedaba apartado del nombramiento, mientras se ofrecía una apariencia de respetar la norma.

\begin{abstract}
"Todos los más beneficios del patronazgo de S.M. estaban proveídos por vicarios en ínterin, porque con este modo de provisión se podían remover y poner otros a la voluntad de los prelados sin intervenir el virrey como patrón, y cuando alguno se nombraba para presentar, era por un testimonio de un notario que decía que el arzobispo había examinado a fulano y a uno se ponía en primer lugar y a otro en segundo sin declarar las partes de cada uno para que el virrey pudiera hacer elección conforme a lo dispuesto por el patronazgo"31.
\end{abstract}

El virrey recordó a los prelados la forma en que debían seguirse las presentaciones y nombramientos. Al mismo tiempo, encontró un medio para desalentar estas prácticas, ordenando que a los beneficiados que no hubiesen sido presentados por el virrey y mantuvieran la condición de interinos, no se les pagase más que dos meses de sueldo, tiempo suficiente para que los prelados corrigieran la situación. A pesar de todo, en los advertimientos a su sucesor, reconocía el escaso éxito de sus disposiciones:

\footnotetext{
${ }^{30}$ CUEVAS, Mariano. Historia de la Iglesia en México. Ciudad de México: Editorial Patria, 1946, p. 53.

${ }^{31}$ Memorial del Marqués de Villamanrique. 1592, en HANKE, Lewis. Los virreyes españoles en América. Op. cit., vol. I, p. 283.
} 


\begin{abstract}
"Porque tenían por costumbre poner vicarios en los partidos y sin tener presentación cobraran los salarios, y además de esto mandé a los corregidores que no los admitiesen al uso de sus oficios pasados los dos meses, con que se ha remediado alguna parte, aunque he despachado mil provisiones para que me envíen razón de la prebendas, beneficios y capellanías de sus iglesias, no ha habido remedio" 32 .
\end{abstract}

Villamanrique se mostró inflexible en cuanto al derecho de presentación que le otorgaba el Patronato, actitud que estima motivo de haberse granjeado la animadversión de los eclesiásticos que, "con esto quedaron los prelados tan sentidos de mi como si se les hubiera hecho alguna ofensa, y en las Indias, aunque no se haga sin justicia, de solo quitarles una costumbre, quedan perpetuamente indignados"33.

El ejercicio del derecho de presentación también ofrecía al virrey posibilidades de proteger sus intereses y reforzar sus propias redes clientelares. A la llegada de Villamanrique, el obispado de Michoacán estaba encomendado a Juan de Medina Rincón, de la orden de los agustinos. Con motivo de su fallecimiento en 11 de julio de 1588, el virrey escribía al rey proponiendo un candidato para la sucesión:

"En la provincia de Nicaragua esta por ob(is)po don fray Domingo de Ulloa, hermano del marqués de la Mota, de quien V.Magd. tiene particular noticia, yo la tengo de que después que llegó allí ha procedido como debe y muy como buen perlado y pues esto su nascim(ien)to meresçe que V.Magd. se acuerde de hazelle mayor merced por ser aquella iglesia tan tenue"34.

Esta promoción, desde tan "tenue" iglesia hasta la importante sede de Michoacán, habría supuesto un notable ascenso para el candidato y reforzado la lealtad del marqués de la Mota, Rodrigo de Ulloa, hacia el virrey. Sin embargo, la candidatura fue rechazada, coincidiendo con su relevo en el virreinato; en su lugar, se nombró al dominico Alonso Guerra en 1591.

\title{
7. Tensiones con el clero secular y regular
}

Los primeros religiosos en llegar a Nueva España fueron los franciscanos, en 1524, seguidos por los dominicos en 1526, los agustinos en 1533 y los jesuitas en 1572. Por último, llegaron los carmelitas, en 1585. En las diócesis, el clero secular se ocupaba del servicio de las catedrales y parroquias de españoles mientras el quehacer misionero con la población indígena recayó principalmente en las órdenes regulares $^{35}$. Sin embargo, en muchas ocasiones, sus funciones se veían afectadas por intromisiones mutuas, cuando las órdenes se hacían cargo de parroquias o los seculares asumían labores misioneras. Esta situación provocaba inevitablemente conflictos de intereses que hacía necesaria la intermediación del virrey, que disponía

\footnotetext{
${ }^{32}$ Advertimientos del marqués de Villamanrique a Luis de Velasco. 14 de febrero de 1590, en Ibídem, p. 282.

${ }^{33}$ Memorial del Marqués de Villamanrique. 1592. Ibídem, p. 285.

${ }^{34}$ AGI, México, 21, 42. Carta del marqués de Villamanrique al rey. México, 11 de julio de 1588.

${ }^{35}$ Para la emigración de religiosos a América, vid. BORGES MORÁN, Pedro. El envío de misioneros a América durante la época española. Salamanca: Universidad Pontificia de Salamanca, 1977.
} 
para ello de unas cédulas reales con disposiciones, muy a menudo, contradictorias. Las instrucciones que recibió Villamanrique para ejercer su cargo especificaban: "Y porque si entre los prelados y religiosos de aquellas partes hubiese alguna diferencia (que no creo), podrá haber muchos inconvenientes [...]. Si tal acaeciere, procurareis como se remedie" ${ }^{\prime 36}$; mientras que en otra cédula prohibía que el virrey y audiencia "se entremetan en asuntos internos de las órdenes religiosas"".

Esta ambigüedad propiciaba una interpretación de las normas según cada circunstancia concreta. A pesar de la cercanía del virrey a las órdenes regulares, especialmente la de San Francisco, también tuvo que intervenir para corregir algunos abusos en que incurrían los frailes en los ámbitos de actuación que les estaban encomendados.

El problema de las doctrinas a cargo del clero regular venía de antiguo, por las desavenencias entre los superiores de las órdenes y los obispos en cuanto a nombramientos de párrocos de indios. En la Real Cédula del Patronato de 1574 se estipulaba que ningún religioso viajara a las Indias sin obtener el permiso del Consejo de Indias. Por otra parte, a su llegada a Nueva España debían presentarse ante el virrey y la audiencia las listas de los religiosos que estaban en conventos y doctrinas; además se especificaba que no podían ser removidos de sus puestos sin ser sustituidos y de todo ello debía darse parte a la audiencia.

Sin embargo, la orden tuvo una notable oposición y no se cumplía habitualmente. Ya el virrey Martín Enríquez escribía a su sucesor:

"[...] quiero decir que lo tocante a los religiosos es aquí muy diferente de España, porque allá ya V.S. sabe que con estarse el religioso en su casa o acudir alguna vez a alguna obra de caridad cuando se ofrece, cumple con su obligación. En solo esto se encierra lo que hay que dar ni tomar con ellos, mas acá, con la falta de clérigos ha sido siempre forzoso que frailes hagan oficios de curas y que S.M. se valga de ellos para la doctrina de los indios" ${ }^{\prime 3}$.

La necesidad de clérigos hizo inviable la aplicación estricta de las normas y las desavenencias continuaron durante el mandato del conde de Coruña, agravadas por la gran fuerza que fue adquiriendo el clero secular durante el mandato de Moya de Contreras y las discrepancias entre el obispo y los superiores de las órdenes, en cuanto a las designaciones y subordinación de los párrocos de indios.

Uno de los motivos de desapego de los regulares hacia Villamanrique se derivó de su financiación. Los religiosos recibían un sueldo por doctrina, además de una limosna de la Real Hacienda. La cantidad que debían percibir se determinaba en proporción al número de indios que cada uno tenía a su cargo. A raíz de la epidemia de 1576 la población indígena había quedado notablemente reducida, razón por la

\footnotetext{
${ }^{36}$ Instrucciones al marqués de Villamanrique. Madrid, 1 de marzo de 1585, en HANKE, Lewis. Los virreyes españoles en América. Op. cit., vol. I, p. 253.

${ }^{37}$ AGI, México, 1064, ff. 194v.-204r. Real cédula al marqués de Villamanrique. Madrid, 18 de febrero de 1588.

${ }^{38}$ Advertimientos de Martín Enríquez al Conde de La Coruña, su sucesor. 25 de septiembre de 1580, en HANKE, Lewis. Los virreyes españoles en América. Op. cit., vol. I, p. 205.
} 
cual los frailes tenían menos indios a su cargo y, por lo tanto, debía reducirse la cantidad que recibían de la hacienda real. En este sentido escribió Villamanrique una proposición al monarca, en una carta de 4 de febrero de 1587, relatando la circunstancia añadida de que los religiosos habían comenzado a fundar "haciendas de granjería" en las que se beneficiaban del trabajo de los indios ${ }^{39}$. El virrey esgrimía esta situación para justificar la reducción de la limosna, ya que no la necesitaban para su sustento. Esta carta propició una consulta del rey a la audiencia y al arzobispo, pidiendo su opinión sobre si "sería bien se vajase a todos los dichos clérigos la limosna conforme a los indios que huvieren faltado" ${ }^{\prime 40}$. Obviamente, la propuesta del virrey no fue bien acogida por los religiosos, que le hicieron responsable de la medida, a pesar de que esta tuviera el visto bueno de la audiencia y el arzobispo.

Todavía se produjo otra intervención virreinal referente a las actuaciones de los religiosos, esta vez dirigida a recortar las licencias que se permitían en las encomiendas. En sendas cartas al monarca de 23 de febrero y 10 de mayo de 1586, Villamanrique expuso al rey la excesiva libertad que tenían los clérigos "para tratar y contratar, de donde tanto daño resulta a los indios, demás de ser cossa tan indecente a la dignidad de su estado sacerdotal" ${ }^{\prime 4}$. La cuestión de las transacciones de los clérigos con los encomenderos ya se había producido anteriormente en Guatemala y se había cursado la correspondiente al obispo para que pusiera límites en su diócesis. Nuevamente en esta ocasión se mostró de acuerdo con el juicio del virrey y otorgó una real cédula, ampliando la orden que había dado para Guatemala, a fin de que tuviera efecto en Nueva España y todas las Indias, en la que se especificaba que los clérigos "no puedan ser factores de los encomenderos ni de otras personas, ni tratar ni contratar por si ni por ynterpositas personas, dirigidas a los prelados encargándoles que castiguen con rigor a los que hizieren lo contrario" ${ }^{, 42}$.

También en las parroquias encomendadas al clero secular se inmiscuían los regulares que, a partir de las doctrinas de indios, tendían a dominar todos los campos de acción. Ya en tiempos del virrey Martín Enríquez se habían dado disposiciones al respecto, pero no fueron acatadas y el problema seguía sin solución. En julio de 1585 Felipe II escribía al arzobispo de México para "que provea lo que convenga sobre que los religiosos de la orden de Sant Francisco y San Agustín tienen ocupadas una hermita y una parrochia de aquella ciudad y conviene que buelban al estado que antes estaban" ${ }^{43}$.

A principios de 1586, Villamanrique intentó solucionar el asunto notificando de nuevo a los franciscanos, dominicos y agustinos las órdenes reales dirigidas al virrey Enríquez. La negativa de los religiosos a obedecerlas se basó en idénticas argumentaciones, sobre la necesidad de ejercer un mayor control sobre la

\footnotetext{
${ }^{39}$ AGI, México, 21, N. 3. Carta del marqués de Villamanrique al rey. México, 4 de febrero de 1587.

${ }^{40} \mathrm{AGI}$, México, 1064, f. 219. Real cédula al marqués de Villamanrique. San Lorenzo, 29 de junio de 1588.

${ }^{41} \mathrm{AGI}$, México, 20, 122. Carta del marqués de Villamanrique al rey. México, 10 de mayo de 1586.

${ }^{42}$ AGI, México, 1064, ff. 194-204. Real cédula al marqués de Villamanrique. Madrid, 18 de febrero de 1588.

${ }^{43}$ AGI, México, 1064, f. 166. Real cédula de Felipe II a Pedro Moya de Contreras, arzobispo de México. Monzón, 14 de julio de 1585.
} 
catequesis y educación en la doctrina de los indios que, según ellos, no ejercerían adecuadamente los seculares. Ante la insistencia del virrey, el asunto rebasó los límites locales para llegar a manos de los provinciales de las órdenes. La secularización de los curatos administrados por religiosos supondría uno de los puntos más polémicos en las relaciones entre ambos cleros y requirió la intervención de los visitadores de las órdenes. El problema aún seguía sin solución definitiva al finalizar el mandato de Villamanrique.

\section{Controversia en la orden franciscana}

Entre los años 1584 a 1587 se dio una sucesión de enfrentamientos dentro de la orden franciscana, entre fray Alonso Ponce, recién nombrado comisario general, y fray Pedro de San Sebastián provincial en Nueva España, con motivo de la visita que el primero emprendió en la provincia de Santo Evangelio.

En el fondo de la controversia latía una disparidad de criterios sobre cómo debía constituirse la institución eclesiástica en Indias. Por una parte, estaban los que sustentaban la idea de una Iglesia colonial, dependiente de la metrópoli, concediendo la primacía al clero secular. Frente a ellos, los defensores de una comunidad eclesial integrada en la población indígena, que respondiera a la peculiar idiosincrasia de los nativos, con predominio del clero regular y bajo el auspicio del virrey ${ }^{44}$. Esta era la lucha que dividía a los religiosos, entre los partidarios de mantener la supremacía de los peninsulares y los que pretendían reforzar la influencia de los religiosos nativos ${ }^{45}$. Fray Gerónimo Mendieta lo explicaba afirmando que iban "[...] contra el sentimiento de todos los padres viejos y expertos que ha habido en esta tierra, que uniformiter sintieron que cuando la religión de San

\footnotetext{
${ }^{44}$ Estas eran las ideas de los llamados 12 apóstoles, los primeros frailes franciscanos que desembarcaron en Nueva España llegados de la Península, herederos de la reforma liderada por Cisneros y del convento de san Gabriel, con tesis milenaristas y un arquetipo que se remitía al cristianismo primitivo, que acentuaba el retorno a la pobreza, la disciplina y el ascetismo, "siendo nro. vestuario y desnudez y caminos bien diferentes que lo que nra religión alla usa, sin punto de propiedad, de suerte que, a dicho de todos, esta era una de las más perfectas provincias de la orden". La frase, que insiste en marcar la diferencia con la evolución de la orden en la Península, pertenece a una carta de 8 de noviembre de 1586, remitida al rey por el provincial San Sebastián, Oroz y Sahagún. AGI, México, 287; en BAUDOT, Georges. Los últimos años de Fray Bernardino de Sahagún o la esperanza inaplazable. Nuevos documentos inéditos. Cahiers du Monde Hispanique et LusoBrésilien. 1974, n. 23, p. 31.

${ }^{45}$ Las primeras propuestas de formar un clero indígena fueron rechazadas radicalmente en el primer concilio mexicano de 1555, en el que se declaró que indios, mestizos y mulatos estaban excluidos de poder recibir las órdenes religiosas. Esta decisión se ratificó en el segundo concilio. Solo en el tercero se suavizó la declaración, aceptando la posibilidad de aceptar a los mestizos, siempre sometidos a una profunda investigación de su linaje. Sobre los concilios provinciales en México, vid. CARRILLO CÁZARES, Alberto. Manuscritos del concilio tercero provincial mexicano (1585). Zamora; Michoacán: El Colegio de Michoacán, 2006; LLAGUNO, José A. La personalidad jurídica del indio y el Tercer Concilio Provincial Mexicano (1585). Ciudad de México: Porrúa, 1963; DUSSEL, Enrique. Los concilios provinciales de América Latina en los siglos XVI y XVII. En: El episcopado latinoamericano y la liberación de los pobres 1504-1620. Ciudad de México: Centro de reflexión teológica, 1979; MOUTIN, Osvaldo R. La tarea legislativa del Tercer Concilio Provincial Mexicano (1585). Hipótesis de trabajo sobre un modo de resolución de conflictos. LOEWE-Schwerpunkt "Außergerichtliche und gerichtliche Konfliktlösung": Arbeitspapier = LOEWE research focus "Extrajudicial and judicial conflict resolution" [documento de trabajo]. 2013, n. 11.
} 
Francisco en Indias deje de ser cebada con frailes de España, será cosa perdida $[\ldots]^{346}$.En contra de esta opinión había figuras notables, de la talla de fray Bernardino de Sahagún o, años antes, fray Toribio de Benavente, Motolinía, preocupados por conseguir una incardinación de la orden en la población nativa. Frente a ellos, el arzobispo era partidario de que el clero seglar fuera, paulatinamente, sustituyendo a los religiosos, secularizando las doctrinas.

Lo que aparentemente iba a ser solo una disputa entre religiosos derivó en consecuencias de mayor calado, incluso político, que afectaron al virrey. Se vertieron unas graves acusaciones contra él en un proceso ante la Inquisición que, aunque finalmente desestimado, dejó una sombra de duda sobre sus lealtades. Los hechos hacen pensar, por tanto, que la cuestión no se reducía a un simple antagonismo entre dos formas de entender la evangelización, sino en argumentos que afectaban al orden político.

Se hace necesario un breve apunte sobre el territorio que constituía la provincia de Santo Evangelio. Fundada en 1524, a la llegada de los primeros frailes franciscanos, era la más rica de la Nueva España:

"[...] incluie en si las tierras mas abastecidas y mas pobladas de las Indias, [y pertenecían a ella] mas de sesenta conventos y monasterios, e incluie en su ámbito y contorno el Arçobispado de Mexico y el Obispado de Tlascalla. Tiene longitud de oriente a poniente de ochenta leguas y de latitud tiene otras treinta leguas [...]. Su convento primero, y principal, es el de la ciudad de Mexico, donde asiste el virrey, la Audiencia y Santa Inquisicion" ${ }^{\prime 47}$.

Por tanto, no es de extrañar el interés de Ponce por conseguir el control de una provincia de tal magnitud e influencia, tanto en el aspecto espiritual, como en el político y económico.

El padre Ponce llegó a México en 1584 con la intención de visitar las provincias del virreinato. Era amigo del arzobispo Moya de Contreras y, como este, partidario de fortalecer el clero secular, por lo que recibió su apoyo desde el primer momento, "fundado el arçobispo en ynteres propios, por que por el amistad que le hazia el comisario le quiso dar la mitad de los conventos y doctrinas desta provincia, contra

${ }^{46}$ CUEVAS, Mariano. Documentos inéditos del siglo XVI para la Historia de México. Ciudad de México: 1914, p. 298. Mendieta, discípulo de Motolinía, demostró su prudencia evitando intervenir en la disputa. Había sido amigo de Ovando y a la muerte de este, conoció de cerca los grandes cambios que se produjeron en la política americana del Consejo de Indias a partir de 1577, cuya primera víctima fue el propio Sahagún, con la confiscación de sus trabajos etnográficos, según refiere BAUDOT, Georges. Los últimos años... Op. cit., p. 36. Sobre su figura y pensamiento político, vid. GONZÁLEZ CÁRDENAS, Luis. Fray Jerónimo de Mendieta, pensador político e historiador. Revista de Historia de América. 1949, n. 28, pp. 331-376.

47 TORQUEMADA, Fr. Juan de. Monarquia Indiana. Los veinte y un libros rituales y Monarquia Indiana, con el origen y guerras de los indios occidentales, de sus poblazones, descubrimiento, conquista, conversión y otras cosas maravillosas de la misma tierra, 1615. Ciudad de México: Universidad Nacional Autónoma de México, 1975, p. 304. 
la real cedula de V.M."

El comisario fue recibido solemnemente en el colegio del convento de Santiago de Tlatelolco, cuyos alumnos le ofrecieron una actuación demasiado indigenista para el parecer del homenajeado, que expresó su disgusto ${ }^{49}$. De esta manera comenzaron las discrepancias con el provincial de México ${ }^{50}$. A partir de ese momento, Ponce inició su visita en franca oposición con el provincial, alargándola más allá de lo establecido, desautorizando a fray Pedro de San Sebastián y otros guardianes de conventos, e interviniendo en temas que escapaban a su cometido. Uno de ellos fue especialmente conflictivo y levantó un notable revuelo entre la población indígena, cuando el comisario dio instrucciones para efectuar un recuento de indios, medida que alarmó a los nativos, que identificaban los recuentos con subida de impuestos:

"[...] particularmente se entremetio en dar patentes para que los guardianes de los pueblos contasen los indios que avia en ellos, cossa que si no es V. Magd. o el que govierna este reyno en su real nombre no lo puede ni debe hazer otro. Y desto nacio entre los indios grandissimo desasosiego porque entendieron les andavan contar pa(ra) cargalles nuevo tributo"51.

Las injerencias del comisario en asuntos como este, llegaron a provocar situaciones de inquietud, no solo entre la población india sino también entre los religiosos a quienes estaba encomendada, de manera que los frailes pidieron la intervención de la audiencia de México. Tras estudiar el caso, el Tribunal dictaminó a favor de los frailes, instando a Ponce a que finalizase su visita por haber sobrepasado ampliamente el plazo concedido para ella, que se limitaba a seis meses. La sentencia obligaba al comisario a dejar la provincia, circunstancia que según esperaban los hermanos, supondría el retorno de la tranquilidad:

"[...] avian acudido a la $\mathrm{R}(\mathrm{ea}) \mathrm{l}$ audiencia pidiendo se le mandase que guardase los estatutos de su orden que son que seis meses antes del capitulo avise el provincial al comis(ari)o pa(ra) que entonces en estos seis meses el haga la visita y acabada haga su capitulo y provea en el provincial y los demás offiçios. Y la

${ }^{48}$ AGI, México, 287. Carta a Felipe II de Fr. Pedro de San Sebastián, Fr Pedro de Oroz, Fr. Bernardino de Sahagún y otros. México, 16 de abril de 1587. Como se ve, el problema de la secularización de las parroquias encomendadas a los religiosos seguía latente a lo largo de los años.

49 Patrocinado por el obispo de México Zumárraga y el virrey Mendoza, el colegio de Tlatelolco fue fundado en 1536. Desde su origen, el propósito del colegio era la educación de jóvenes nativos, especialmente hijos de los nobles locales, a quienes se impartían enseñanzas de latín, filosofía y teología, instrumentos necesarios para la formación de un clero local. Allí enseñaba fray Bernardino de Sahagún y algunos de sus discípulos colaborarían con él en sus investigaciones sobre la lengua y la cultura náhuatl, que culminaron en la redacción de la Historia general de las cosas de la Nueva España; vid. OLIVEIRA FERNANDES, Luiz Estevam y DOS REIS, Anderson Roberti. Os conflitos e as possibilidades de paz: as concepçôes políticas de Motolinía e Mendieta no México do século XVI. Revista Eletronica da ANPHLAC. 2006, n. 5, pp. 1-24. [Consulta: 16 diciembre 2016]. Disponible en: <http://revistas.fflch.usp.br/anphlac/article/view/1367>.

${ }^{50}$ En este caso, como afirma Baudot, "el peninsularismo del P. Ponce no es sino 'anti-indigenismo' declarado, lo que, en 1584, seis años después de las censuras que raptan la obra de Sahagún, y en un alto cargo procedente de la metrópoli, es bastante plausible"; BAUDOT, Georges. Los últimos años... Op. cit., p. 26.

${ }^{51}$ AGI, México, 20, 119. Carta del marqués de Villamanrique al rey. México, 17 de diciembre de 1585. 
Real Audiencia le avia mandado conformidad desto que hiziese su visita y la acabase dentro de los seis meses y que pasado este tiempo se saliese a visitar otra provincia. $Y$ aviendose pasado los seis meses con todo esto pretende estarse mas tiempo"

Estos hechos habían sucedido antes de la llegada de Villamanrique, quien mantenía una estrecha relación con la orden de San Francisco, a la que era muy afecto ya desde su infancia en España, al igual que su familia ${ }^{53}$. Durante su estancia en México, numerosos testimonios dan cuenta de la familiaridad, tanto suya como de la marquesa, con los frailes de la orden y, más concretamente, la asiduidad del virrey en el trato con Sahagún. En sus viajes solían alojarse en el convento de Xochimilco y visitaban con frecuencia el colegio de Tlatelolco. Del mismo modo que sus antecesores en el virreinato, Villamanrique apoyaba la causa de los franciscanos, que también propugnaba el fortalecimiento de la autoridad virreinal ${ }^{54}$. Por eso, no es de extrañar que el provincial recurriese al virrey para recabar su apoyo en la disputa. Según relataba al rey:

"Quando aquí llegue halle la orden de S Fran(cis)co alborotada y en tanta manera que fue menester poner todos los medios posibles $p($ ara) aquietalla [...]. La causa desto era el modo de proceder que con ellos tenia fray Alonso Ponçe, comisario general, el qual ha ya año y medio que vino de ese reyno a visitar los monesterios deste, y todo este tiempo se a estado en esta provincia, sin querer salir della, teniendo opresos al provincial y guardianes, quitándoles en todo el gobierno de la orden"55.

El virrey estudió el asunto y recabó el parecer de la audiencia, que le informó de la sentencia dictada y de la renuencia del clérigo a acatarla. A petición de los frailes se entrevistó personalmente con Ponce para instarle al acatamiento de lo dictado por el tribunal:

"[...] de manera que los frayles tornaron a ocurrir a el audiencia y a pedirme a mi que los remediase y por el acuerdo se determino que cumpliese lo mandado y por guardarle el decoro que se debe a la autoridad de su offiçio yo no quise que fuese por esta via y de mi a el le dixe que el audiencia avia mandado aquello y que estaba muy en rrazon el cumplirlo"56.

Sin embargo, Ponce no estaba dispuesto a ceder y no solo no abandonó la provincia, sino que continuó dictando patentes en contra del provincial y los dirigentes de la orden. En una carta a Felipe II el mismo fray Bernardino de Sahagún se refería a la situación:

\footnotetext{
${ }^{52}$ Ibídem.

${ }^{53}$ Su antepasado Gutierre de Sotomayor, fray Juan de la Puebla al entrar en religión, fue un gran reformador y fundador de numerosos conventos. Su abuelo paterno, tras enviudar, ingresó también en la orden.

${ }^{54}$ El apoyo del virrey a los franciscanos también provocó un incidente con el cabildo de la ciudad, cuando los frailes reclamaron la propiedad y custodia de la Virgen de los Remedios de Guadalupe, alegando haber sido hallada en terrenos encomendados a la orden; vid. CARRILLO PÉREZ, Ignacio. Lo máximo en lo mínimo. La portentosa imagen de Nuestra Señora de los Remedios, conquistadora y patrona de la imperial ciudad de México. Ciudad de México: Mariano de Zúñiga, 1808.

${ }_{55} \mathrm{AGI}$, México, 20, 119. Carta de Villamanrique al rey. México, 17 de diciembre de 1585.

${ }^{56}$ Ibídem.
} 
"N(uest)ros graves pecados o la embidia de Satanás an sido causa de que este feliçe estado aya perdido su figura, obscurecida la perfection, la paz, la charidad y observancia regular con el Comissario llamado Fray Alonso Ponce que a dos años que aquí vino. El qual es de tal condición que ni n(uest)ros clamores, ni los ruegos y mandatos de v(uest)ro pacifico Vissorey y Real audiencia, an sido ni son poderosos para meterle por camino"57.

Hubo un nuevo apercibimiento por parte del virrey, aunque ya avisaba al monarca de que habría de recurrir a medidas más drásticas para conseguir que saliera de la provincia.

"Estubose muchos días que no lo hizo, antes persevero en su modo de proceder,
y yo le torne a llamar y a pedir hiziese lo que tenia dicho, y con todo esto ha mas
de quarenta días que sesta aquí sin cumplir lo que se le mando, teniendo a la
orden desta provi(nci)a en grandissima inquietud. Si passa adelante su
inobediencia se abra de proceder por otro camino hasta hechallo de aquí, pues no
a querido hazello por el que se a guiado con tanta consideración y conviene
mucho hazerse desta manera porque mientras este fraile estuviere en esta
provi(nci)a traerá a la orden grandissima inquietud y desasosiego"58.

La advertencia del virrey no resultaba ociosa, ya que Ponce continuó adoptando decisiones conflictivas. En marzo de 1586, dictó la destitución del provincial y dispuso que fuera sustituido por fray Bernardino de Sahagún e instando a los padres a acatar sus disposiciones, bajo pena de excomunión, en un intento de neutralizar a sus opositores. Sahagún renunció al cargo y expresó su apoyo a Fray Pedro de San Sebastián y Ponce abandonó la provincia camino de Guatemala, pero siguió enviando patentes a los conventos conminándoles a desobedecer al provincial ${ }^{59}$.

La intervención del virrey fue inmediata, ordenándole entregar las cartas para ser examinadas por él mismo y por la audiencia antes de remitirlas a los conventos, pero la reacción de Ponce fue de desacato y rebeldía, lo que propició que el virrey decretara su detención, junto a los frailes que le acompañaban, enviándolos a Veracruz a la espera de la salida de la flota, para su expatriación a España:

"Y por evitar el escandalo que pudiera subceder yo ynvie a notificalles que so pena de ser avidos por estraños de los reynos de V.Magd. que no yntimasen en ninguna manera las patentes que trayan hasta questa $R(e a) l$ Audiencia y yo las viésemos. $Y$ al tiempo que se les hizo esta notificación, respondieron por escripto tantas desenvolturas y libertades [...] porque ellos no tenían mas obligación que obedecer a su perlado y no a los mandam(ien)tos de V. Magd ni de sus R(ea)les ministros. Y para castigo suyo y exemplo de otros, por aver sido el caso tan publico, se envían en esta flota y con esta va el proceso de sus culpas y el de los

\footnotetext{
${ }^{57}$ AGI, México, 287. Carta a Felipe II firmada por varios frailes: Pedro de San Sebastián, Pedro de Oroz, Bernardino de Sahagún, Rodrigo de San Luis, Pedro de Requena, Francisco Vázquez. México, 8 de noviembre de 1586.

${ }^{58}$ AGI, México, 20, 119. Carta del marqués de Villamanrique al rey. México, 17 de diciembre de 1585.

${ }^{59}$ AGI, México, 20, 122. Carta del marqués de Villamanrique al rey. México, 10 de mayo de 1586. "[...] aviendose ydo el comisario en prosecución de lo que se le mandó, a visitar la provincia de Guatemala, desde el camino ynvio unas patentes en que mandava no obedeciesen al provincial, con que volvió a escandaliçar otra vez la orden que estaba ya quieta con su ausencia".
} 


\section{desordenes del comisario"60.}

Llegado el conflicto a estos extremos, es cuando aparece un llamativo proceso de la Inquisición, iniciado en el mismo mes de abril de $1586^{61}$. Fue incoado contra el provincial fray Pedro de San Sebastián y en él se vieron envueltos también fray Pedro de Oroz, fray Bernardino de Sahagún y fray Alonso de Molina ${ }^{62}$, salpicando de paso al virrey como sospechoso de colaborar con los procesados. Las acusaciones, basadas en las declaraciones de los frailes detenidos, son singularmente graves y recuerdan a las que años antes se vertieron contra Motolinía: "en resumidas cuentas, considerar a México como una entidad política autónoma, tanto en lo político como en lo religioso, y hacer del virrey su cabeza visible" ${ }^{\prime \prime 3}$.

Quizá conviene recordar que la Inquisición estaba en manos de Moya de Contreras, arzobispo de México y ex virrey. Llama la atención la diligencia en las actuaciones en dicho proceso, ya que la toma de declaraciones a los testigos se hizo en las mismas semanas en que se estaba desarrollando el conflicto. Los franciscanos, que estaban presos en la fortaleza de San Juan de Ulúa, a la espera de su repatriación a España, testificaron el 11 de abril de 1586, refiriendo haber oído frases heréticas de boca de sus superiores. La primera denuncia la efectúa Antonio de Torres, cura en San Juan de Ulúa, que relata:

"[...] estos $p(a d r) e s$ religiosos de $S(a n)$ Fran(cis)co que por orden del virrey vinieron presos a esta isla para ser imbiados a España, he oydo referir a algunos de sus frayles, en especial del guardián de México y del de Guamantla, palabras muy escandalosas y propositiones muy malsonantes, en razón de hazer poco caso de las censuras eclesiásticas, y de hazer cabeza de estos Reynos de lo temporal y espiritual al Virrey, lo qual es heregia lutherana, y que agora tanto corre en Inglaterra".

Los frailes declaraban también que estaban en el convento de San Francisco de México cuando llegó la patente de Ponce, por la que destituía de su cargo de provincial a fray Pedro de San Sebastián y nombraba a fray Bernardino de Sahagún, a cuya recepción el guardián del colegio pronunció frases comprometedoras. Se ordenaba en ella al guardián del convento de Santiago:

"[...] a fray Pedro de Oroz diese favor y ayuda para que la dicha patente se notificase, so la dicha pena de excomunión mayor [...] a lo qual el dicho padre Fray $\mathrm{P}$ (edr)o de Oroz respondio que la obedecería si el S(eñ)or Virrey se lo mandase [...] que donde el Virrey entraba de por medio no havia excomunión ni obediencia de perlado [...] dixo por dos veçes: aquí tenemos una cabeça a quien obedescer que es el señor virrey".

\footnotetext{
${ }^{60}$ Ibídem.

${ }^{61}$ Archivo General de la Nación de México (en adelante AGNM), Inquisición, vol. 120, doc 12. En el margen figura una nota: "no se siguió".

62 Fray Alonso de Molina, dedicado al estudio de la lengua náhuatl, compuso el primer diccionario español-náhuatl titulado Vocabulario en Lengua Castellana y Mexicana.

${ }_{63}$ BAUDOT, Georges. Los últimos años... Op. cit., p. 27. Para el caso Motolinía, vid. BAUDOT, Georges. Le 'complot' franciscain contre la première audience de Mexico. Cahiers du Monde Hispanique et Luso-Brésilien. 1964, n. 2, pp. 15-34.
} 
Más adelante se recoge una declaración que pone en boca de fray Pedro de San Sebastián las palabras "que no había otro Papa en la Indias sino el virrey", e inculpa a fray Alonso de Molina por su prefacio al Vocabulario en Lengua Castellana y Mexicana en que "dize estas palabras dirigiéndose el dicho libro al virrey: siendo V. Exa. Cabeça desta nueva iglesia" ${ }^{4}$.

El proceso no siguió adelante, pero la situación dentro de la orden seguía muy alterada. Mientras tanto, el arzobispo Pedro Moya de Contreras regresó con la flota a España para dar cuenta al monarca de los resultados de la visita, en tanto que la orden franciscana en Nueva España seguía sumida en la controversia. El marqués tomó la decisión de convocar a los superiores de la orden para intentar pacificar la situación. El 23 de octubre de 1587 escribía a fray Jerónimo Mendieta, expresando que "yo deseo la quietud de esta provincia, como hijo verdadero de nuestro padre Sant Francisco" y la necesidad de dirimir las diferencias surgidas en la orden por "algún otro medio que sea mas conveniente". Con tal motivo le convocaba a una reunión:

"[...] y para esto tengo necesidad de que vr se venga para mi y este en esta ciudad el dia de todos Sanctos, que es para quando he hecho llamar a algunos otros padres graves de esta provincia para que con el consejo y parecer de todos se ordene lo que mas convenga" ${ }^{\prime 65}$.

En efecto, el 2 de noviembre de 1587 se reunieron las autoridades seráficas para redactar un testimonio oficial sobre el caso, en el que la mayoría de los declarantes apoyó las tesis de Sahagún ${ }^{66}$.

\section{Conclusiones}

Las cuestiones desarrolladas a lo largo de este artículo son solo algunas muestras de los numerosos desencuentros entre el virrey marqués de Villamanrique y las instituciones eclesiásticas. En las conflictivas relaciones de la monarquía con la Iglesia en Nueva España a finales del siglo XVI se pueden apreciar dos vertientes, diferentes pero complementarias.

En primer lugar, una que se podría definir como de carácter estructural, en la misma esencia de la organización eclesiástica indiana, marcada por las interferencias que provocaba la existencia del Patronato Regio, circunstancia que a lo largo de los siglos marcó los enfrentamientos entre ambas instituciones y que se

\footnotetext{
${ }^{64}$ BAUDOT, Georges. Los últimos años... Op. cit., p. 29.

${ }^{65}$ British Library, MSS. Harley, 3570, n. 98, f. 301. Carta del marqués de Villamanrique a Mendieta. México, 23 de octubre de 1587.

${ }^{66} \mathrm{AGI}$, México, 21, ramo 3, 21, 23 y 23a. Parecer del virrey favorable a los franciscanos y hostil a Ponce; Carta del virrey de 3 de noviembre de 1587 informando de la reunión y de la hostilidad general de los dignatarios franciscanos hacia Ponce; y Testimonio de los pareceres y votos de los frailes en la junta, respectivamente. "[...] el padre Fray Luis de Villamayor dixo que en todo y por todo se remite y conforma a los paresceres del padre Fray Bernardino de Sahagún [...] y luego el padre Fray Alonso de Paterna dixo que se remite al paresçer de los padres Fray Pedro de Oroz y Fray Bernardino de Sahagún", lo que lleva a afirmar a Baudot que, [...] quizá con la amargura de empezar a comprender el porqué de la confiscación de su trabajo etnográfico"; BAUDOT, Georges. Los últimos años... Op. cit., pp. 35-36.
} 
fue repitiendo en muchos otros momentos, especialmente, cuando sobrevino el gobierno de otros arzobispos virreyes. Si bien no era en modo alguno excepcional, sino más bien una característica en Nueva España, el que un arzobispo asumiera funciones políticas como el virreinato interino, sí lo fue la posición de Pedro Moya de Contreras en estos años, por la insólita acumulación de cargos que reunió, teniendo en sus manos todo el poder político y espiritual.

En segundo lugar, otra de tipo coyuntural: a finales del siglo XVI, la Iglesia novohispana se encontraba inmersa en un proceso de redefinición de sus fines, prioridades y estrategias. A partir de las conclusiones emanadas del Concilio de Trento, el III Concilio Provincial Mexicano se encargaría de definir algunas de esas propuestas. La trayectoria diseñada por los prelados iba dirigida a conseguir una progresiva primacía del clero secular, apoyada por la Santa Sede, en detrimento de las órdenes religiosas que, en el envite, no solo veían ponerse en juego su privilegiada e influyente posición, sino todo un concepto de lo que debía ser la esencia de la labor eclesial en Indias, controversia que se vio acentuada en el seno de la orden franciscana y trascendió hasta afectar políticamente al virrey.

Los enfrentamientos con el arzobispo Moya de Contreras y el obispo de Puebla se sumaron al tenso panorama, definiendo la dirección de sus futuras relaciones. Una serie de episodios puntuales, pero tan decisivos que al fin de su mandato el virrey culpaba a los clérigos de su destitución.

El regreso de Moya de Contreras a España y su posterior nombramiento como presidente del Consejo de Indias, puso en manos del prelado la suerte del marqués, ya que tuvo la posibilidad de influir en el monarca en su decisión sobre la persona a la que se encargaría la visita del virrey. A pesar de la opinión en contra de otros miembros del Consejo, se nombró finalmente a Diego Romano, obispo de TlaxcalaPuebla.

De todo ello se desprende que las controversias con la Iglesia, lejos de ser meras disputas de clérigos, a menudo ocultaban un trasfondo político, capaz incluso de remover ministros reales. E incluso, tras la destitución de Villamanrique, dichas controversias marcarían el sentido de su proceso en el juicio de residencia, con graves consecuencias para el virrey depuesto, a quien se le aplicó sentencia de incapacitación para ocupar puestos y cargos, la pena de destierro y la confiscación de la totalidad de sus bienes.

\section{Bibliografía}

BAUDOT, Georges. Le 'complot' franciscain contre la première audience de Mexico. Cahiers du Monde Hispanique et Luso-Brésilien. 1964, n. 2, pp. 15-34.

BAUDOT, Georges. Los últimos años de Fray Bernardino de Sahagún o la esperanza inaplazable. Nuevos documentos inéditos. Cahiers du Monde Hispanique et Luso-Brésilien. 1974, n. 23, pp. 23-45.

BORGES MORÁN, Pedro. El envío de misioneros a América durante la época 
española. Salamanca: Universidad Pontificia de Salamanca, 1977.

CAÑEQUE, Alejandro. The King's Living Image: The Culture and Politics of Viceregal Power in Colonial Mexico. Nueva York: Routledge, 2004.

CARRILLO CÁZARES, Alberto. Manuscritos del concilio tercero provincial mexicano (1585). Zamora; Michoacán: El Colegio de Michoacán, 2006.

CARRILLO PÉREZ, Ignacio. Lo máximo en lo mínimo. La portentosa imagen de Nuestra Señora de los Remedios, conquistadora y patrona de la imperial ciudad de México. Ciudad de México: Mariano de Zúñiga, 1808.

CUEVAS, Mariano. Documentos inéditos del siglo XVI para la Historia de México. Ciudad de México: 1914.

CUEVAS, Mariano. Historia de la Iglesia en México. Ciudad de México: Editorial Patria, 1946.

DUSSEL, Enrique. Los concilios provinciales de América Latina en los siglos XVI y XVII. En: El episcopado latinoamericano y la liberación de los pobres 1504-1620. Ciudad de México: Centro de reflexión teológica, 1979.

GONZÁLEZ CÁRDENAS, Luis. Fray Jerónimo de Mendieta, pensador político e historiador. Revista de Historia de América. 1949, n. 28, pp. 331-376.

HANKE, Lewis. Los virreyes españoles en América durante el gobierno de la Casa de Austria. Madrid: Atlas, 1977.

HERA PÉREZ CUESTA, Alberto de la. El patronato y el vicariato regio en Indias. En: BORGES, Pedro (dir.). Historia de la Iglesia en Hispanoamérica y Filipinas. Vol 1. Madrid: Biblioteca de Autores Cristianos, 1992.

HERA PÉREZ CUESTA, Alberto de la. El regio vicariato de Indias en las bulas de 1493. Anuario de Historia del Derecho Español. 1959, n. 29, pp. 317-350.

LETURIA, Pedro. EI Regio Vicariato de Indias y los comienzos de la congregación de Propaganda Fide. Spanische Forschungen Der Görresgesellschaft. Vol. I. 1929, pp. 133-177.

LLAGUNO, José A. La personalidad jurídica del indio y el Tercer Concilio Provincial Mexicano (1585). Ciudad de México: Porrúa, 1963.

LUQUE ALCAIDE, Elisa. La Iglesia, semilla de solidaridad universal en la familia humana. En: PELLITERO IGLESIAS: Ramiro (dir.). La Iglesia como familia de Dios. Madrid: Rialp, 2010.

MARTÍNEZ FERRER. Luis. Fuentes e historiografía del III concilio provincial mexicano (1585). En: SARANYANA, Josep Ignasi; LAMA, Enrique de la y 
LLUCH-BAIXAULI, Miguel (eds.). Qué es la historia de la Iglesia: XVI Simposio Internacional de Teología de la Universidad de Navarra. Pamplona: Servicio de Publicaciones de la Universidad de Navarra, 1996, pp. 355-366.

MOUTIN, Osvaldo R. La tarea legislativa del Tercer Concilio Provincial Mexicano (1585). Hipótesis de trabajo sobre un modo de resolución de conflictos. LOEWESchwerpunkt "Außergerichtliche und gerichtliche Konfliktlösung": Arbeitspapier = LOEWE research focus "Extrajudicial and judicial conflict resolution" [documento de trabajo]. 2013, n. 11.

OLIVEIRA FERNANDES, Luiz Estevam y DOS REIS, Anderson Roberti. Os conflitos e as possibilidades de paz: as concepçôes políticas de Motolinía e Mendieta no México do século XVI. Revista Eletronica da ANPHLAC. 2006, n. 5, pp. 1-24. [Consulta: 16 diciembre 2016]. Disponible en: <http://revistas.fflch.usp.br/anphlac/article/view/1367>

ORTIZ TREVIÑO, Rigoberto Gerardo. El Tercer Concilio Provincial Mexicano o como los obispos evadieron el Real patronato indiano. En Anuario Mexicano de Historia del Derecho. 2003, n. 15, pp. 77-94.

PAREDES, Julián. Recopilación de Leyes de los Reynos de las Indias. Mandadas imprimir, y publicar por la magestad catolica del rey don Carlos II. Madrid: por Iulian de Paredes, 1681.

PÉREZ PUENTE, Leticia. Dos proyectos postergados. El Tercer Concilio Provincial Mexicano y la secularización parroquial. Estudios de Historia Novohispana. 2006, n. 35, pp. 17-45.

POOLE, Stafford. La visita de Moya de Contreras. En: Memoria del Segundo Congreso Venezolano de Historia. Vol. 2. Caracas: 1975, pp. 417-441.

POOLE, Stafford. Pedro Moya de Contreras: Catholic Reform and Royal Power in New Spain, 1571-1591. Berkeley; Los Angeles; Londres: University of California Press, 1987.

RAMÍREZ MENÉNDEZ, Jessica. Fundar para debilitar. El obispo de Puebla y las órdenes regulares (1586-1600). Estudios de historia novohispana. 2013, n. 49, pp. 39-82.

RIVA PALACIO, Vicente. México a través de los siglos: el virreinato; historia de la dominación española en México desde 1521 á 1808. Ciudad de México: Cumbre, 1977.

TORQUEMADA, Fr. Juan de. Monarquia Indiana. Los veinte y un libros rituales y Monarquia Indiana, con el origen y guerras de los indios occidentales, de sus poblazones, descubrimiento, conquista, conversión y otras cosas maravillosas de la misma tierra, 1615. Ciudad de México: Universidad Nacional Autónoma de México, 1975. 
TORRES, Pedro. La bula omnímoda de Adriano VI. Madrid: Instituto Santo Toribio de Mogrovejo; Consejo Superior de Investigaciones Científicas, 1948.

VICENS HUALDE, María. Guerra de cortesías: el ceremonial como arma en el conflicto entre el virrey marqués de Villamanrique y el arzobispo Moya de Contreras. Temas Americanistas. 2018, n. 40, pp. 119-139. 